\title{
Ultrasonic Testing of NIF Amplifier FAU Top Plates
}

D. J. Chinn, R. D. Huber, J. J. Haskins, J. A. Rodriguez, P. R. Souza, T. V. Le

\section{May 7, 2002}

U.S. Department of Energy

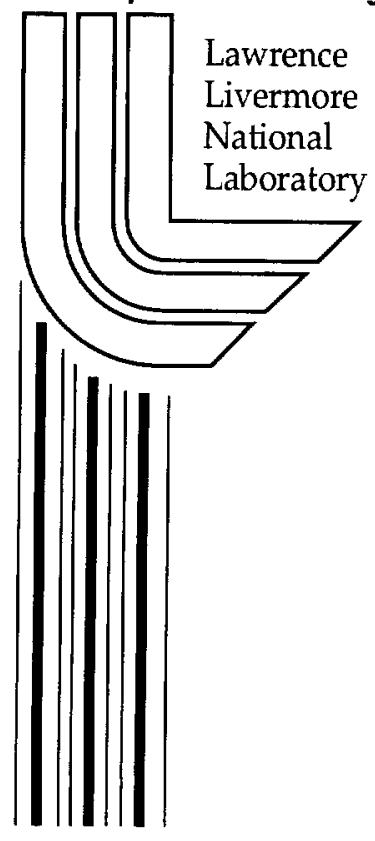




\section{DISCLAIMER}

This document was prepared as an account of work sponsored by an agency of the United States Government. Neither the United States Government nor the University of California nor any of their employees, makes any warranty, express or implied, or assumes any legal liability or responsibility for the accuracy, completeness, or usefulness of any information, apparatus, product, or process disclosed, or represents that its use would not infringe privately owned rights. Reference herein to any specific commercial product, process, or service by trade name, trademark, manufacturer, or otherwise, does not necessarily constitute or imply its endorsement, recommendation, or favoring by the United States Government or the University of California. The views and opinions of authors expressed herein do not necessarily state or reflect those of the United States Government or the University of California, and shall not be used for advertising or product endorsement purposes.

This work was performed under the auspices of the U.S. Department of Energy by the University of California, Lawrence Livermore National Laboratory under Contract No. W-7405-Eng-48.

This report has been reproduced directly from the best available copy.

Available electronically at http://www.doc.gov/bridge

Available for a processing fee to U.S. Department of Energy And its contractors in paper from

U.S. Department of Energy

Office of Scientific and Technical Information

P.O. Box 62

Oak Ridge, TN 37831-0062

Telephone: (865) 576-8401

Facsimile: (865) 576-5728

E-mail: reports@adonis.osti.gov

Available for the sale to the public from

U.S. Department of Commerce

National Technical Information Service

5285 Port Royal Road

Springfield, VA 22161

Telephone: (800) 553-6847

Facsimile: (703) 605-6900

E-mail: orders@ntis.fedworld.gov

Online ordering: http://www.ntis.gov/ordering.htm

OR

Lawrence Livermore National Laboratory

Technical Information Department's Digital Library

http://www.llnl.gov/tid/Library.html 


\title{
Ultrasonic testing of NIF amplifier FAU top plates
}

\author{
Prepared by: \\ Diane J. Chinn, Robert D. Huber \\ Jerry J. Haskins, John A. Rodriguez, Paul R. Souza, \\ and Trung V. Le
}

Manufacturing and Materials Engineering Division

Lawrence Livermore National Laboratory

P. O. Box 808, M/S L-333

Livermore, CA 94550 
I. Introduction .........................................................................................................................

II. Ultrasonic test technique ................................................................................................

II.A. Background ...................................................................................................................

II.B. Description of ultrasonic test ............................................................................4

III. Pre-cyclic test inspection .................................................................................................. 4

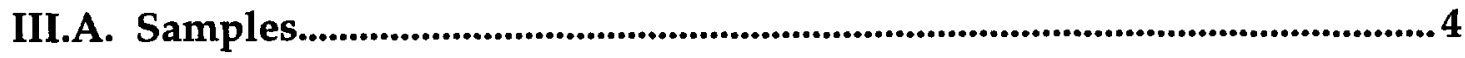

III.B. Results ............................................................................................................................ 5

III.C. Discussion ...............................................................................................................

III.C.1. Plate 6 .............................................................................................................6 6

III.C.2. Plate 7 ..................................................................................................................... 7

III.D. Verification by X-ray computed tomography of core samples................. 7

IV. Ultrasonic field measurements ......................................................................................... 8

IV.A. Measurement error ......................................................................................................9

IV.B. Ultrasonic signal processing ........................................................................9

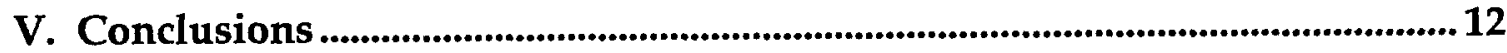

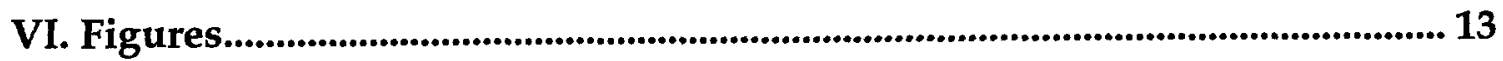




\section{Ultrasonic testing of NIF amplifier FAU top plates}

\section{Introduction}

A key component in the National Ignition Facility (NIF) laser optic system is the amplifier frame assembly unit (FAU). The cast aluminum top plate that supports the FAU is required to withstand loads that would occur during an earthquake with a recurrence period of 1000 years. The stringent seismic requirements placed on the FAU top plate induced a study of the cast aluminum material used in the top plate. Ultrasonic testing was used to aid in characterizing the aluminum material used in the plates.

This report documents the work performed using contact ultrasonic testing to characterize the FAU top plate material. The ultrasonic work reported here had 3 objectives:

1) inspect the plate material before cyclic testing conducted at the Pacific Earthquake Engineering Research Center (PEER)

2) determine the overall quality of individual plates

3) detect large defects in critical areas of individual plates

Section III, "Pre-cyclic test inspection", describes work performed in support of Objective 1. Section IV, "Ultrasonic field measurements", describes work performed in support of Objectives 2 and 3.

\section{Ultrasonic test technique}

\section{II.A. Background}

Contact ultrasonic testing is commonly used for in-situ detection of defects in metallic parts. The contact pulse-echo configuration depicted in Fig. 1 uses a single piezoelectric transducer to send and receive an ultrasonic wave field. Using a thin layer of gel couplant between the transducer and the part, the transducer transmits small displacements onto the surface of the part. The wave field created in the part is coherent at ultrasonic frequencies and is composed of compressional $(\mathrm{P})$ waves. This type of oscillatory wave has particle displacement parallel to the direction of propagation.

A typical waveform from contact ultrasonic testing is also shown in Fig. 1. If a defect is located in the path of the propagating wave, the defect will reflect some of the energy in the wave. Shape and morphology of the defect determine the amplitude of the reflected wave. The amplitude of the reflected wave is measured in volts. Arrival time of the defect reflection, $t_{1}$, depends on the depth of the defect according to $t_{1}=2 d / c$, where $c=$ the sound velocity of P-waves in 
the material and $d=$ the distance between the defect and the transducer. If the defect is much smaller than the beam of the transducer, the rest of the energy in the sound path will continue and will be reflected from the back surface of the part at time $t_{2}$.

\section{II.B. Description of ultrasonic test}

All contact ultrasonic measurements were taken using the setup shown in the photo in Fig. 2. A Panametrics Epoch IV portable flaw detector sends an electronic pulse to the $5 \mathrm{MHz}, 0.5$ " diameter contact piezoelectric transducer generating displacement at the transducer face. UltraGel couplant couples the transducer displacement into the plate. Pulse-echo testing, where one transducer is used to both send and receive the ultrasonic signal, records the backscatter resulting from a P-wave traveling through the part. Full waveforms collected from the portable flaw detector are recorded on a laptop computer. A $0.5^{\prime \prime}$ grid is drawn on the plate in the area of testing and one contact measurement is taken at the intersection of each grid line.

The nominal thickness of the top plate is $63.5 \mathrm{~mm}$, the measured P-wave velocity, $c_{p}$, is $6.8 \mathrm{~mm} / \mu \mathrm{s}$. The wavelength of the P-wave in the aluminum using a $5 \mathrm{MHz}$ transducer, $\lambda_{\mathrm{P}_{5 \mathrm{MHz}}}$ is $1.3 \mathrm{~mm}$. The detection resolution of the transducer is nominally on the order of a wavelength.

\section{Pre-cyclic test inspection}

\section{III.A. Samples}

Two plates were inspected prior to cyclic testing. These plates are denoted Plate 6 and Plate 7. Access to the bottom side of both plates was limited by strain gages and wiring glued on for the cyclic test. The locations of the strain gages and wiring prohibited contact ultrasonic testing from the bottom side of the plates. Consequently, contact ultrasonic inspection was performed from the top side of Plates 6 and 7.

On Plate 6, areas near each of the three ears were marked with a testing grid, $0.5^{\prime \prime}$ on center. The ears, labeled Ear A, Ear B and Ear C, are shown in Fig 3. Ear A is the single ear side, Ear B and Ear C are on the double-eared side of the plate. A large number of data points on each area were taken: Ear A - 593 data points, Ear B - 350 data points, Ear C - 219 data points. Each area took approximately 2 -3 hours to gather data according to the procedure described above. Plate 6 was tested at a flaw detector gain setting of $60 \mathrm{~dB}$.

On Plate 7, Ear A, shown in Fig. 4, was the only ear tested. Ear B and Ear C were not tested because of the presence of strain gages glued to the top and bottom sides of those ears. Plate 7 was tested at $54 \mathrm{~dB}$ flaw detector gain setting. The portable flaw detector used in testing has less than 4-bit dynamic range. When ultrasonic amplitudes vary more than 4-bits (256 levels), the receiver gain on the flaw detector must be changed to amplify or reduce the signal to prevent saturation of the waveform. Upon testing Plate 7, most areas appeared to have 
higher reflected signals than Plate 6 so the gain setting was decreased by $6 \mathrm{~dB}$ to obtain unsaturated waveforms. To compare signals between Plate 6 and Plate 7, one of the data sets must be scaled to the other by $6 \mathrm{~dB}$.

For comparison, the reflections from 5 flat-bottom holes were recorded using the ultrasonic test system at $54 \mathrm{~dB}$ gain. The flat-bottom hole diameters are $0.5 \mathrm{~mm}$, $1 \mathrm{~mm}, 2 \mathrm{~mm}, 3 \mathrm{~mm}$ and $4 \mathrm{~mm}$. The amplitude of reflection from these reference holes are listed in Table 1.

\begin{tabular}{|c|c|}
\hline $\begin{array}{c}\text { Flat-bottom hole dia. } \\
\text { [mm] }\end{array}$ & $\begin{array}{c}\text { Max amp } \\
\text { [volts] }\end{array}$ \\
\hline 0.5 & 13.1 \\
1.0 & 50.2 \\
2.0 & 186.4 \\
3.0 & 412.6 \\
4.0 & 577.0 \\
\hline
\end{tabular}

Table 1. Amplitude of reflection for flat-bottom reference holes at $54 \mathrm{~dB}$ gain.

\section{III.B. Results}

An ultrasonic C-scan image spatially plots the maximum amplitude of the ultrasonic waveform within a specified time period. For Plates 6 and 7 , maximum amplitude, mapped in the C-scan, is an indicator of the size of the largest reflector in the plate at the grid location. Fig. 5 shows $\mathrm{C}$-scan images of Plate 6. The colorbar in Fig. 5A shows the key for amplitude mapping in Figs. 5A-5C. White relates to a high amplitude reflection or a larger defect, red relates to a low amplitude reflection or a smaller defect. The black areas represent no data. Images in Figs. 5A - 5C are mapped to the same color scale. Grid numbers are shown beside the $\mathrm{C}$-scans for easier mapping to the photos in Fig. 3. For reference, the amplitude of reflection from a $1 \mathrm{~mm}$ diameter drilled hole is inserted into the C-scan image in Fig. 5A and is circled in white.

Fig. 6 shows C-scan images of Ear A for Plate 6 and Plate 7 calibrated to the same color scale. Fig. 6A shows the C-scan image for Plate 6 when scaled to $54 \mathrm{~dB}$ using the color scale in Fig. 6B. This is the same data shown in Fig. 5A however the color scale has changed from $60 \mathrm{~dB}$ in Fig. $5 \mathrm{~A}$ to $54 \mathrm{~dB}$ in Fig. 6A. Fig. $6 \mathrm{~B}$ shows the C-scan for Plate 7 at $54 \mathrm{~dB}$.

Waveforms for selected areas on Plate 7 are shown in Fig. 7A-7C. Fig. 7D shows the waveform for a $1 \mathrm{~mm}$ diameter flat-bottom drilled hole. Each time point in Fig. 7 represents $0.035 \mu \mathrm{s}$. The initial pulse incident on the front surface rings down from time point 0 to approximately time point 100 . The back surface reflection begins after time point 500 . Between time points 100 to 500 , backscattered reflections arrive that result from inhomogeneities through the thickness of the material. Backscattered reflections through the thickness can result from porosity, voids, phase transformations at grain boundaries, inclusions or delaminations. In Fig. 7D, the reflected signal from the $1 \mathrm{~mm}$ 
diameter reference hole is shown. Used as a reference signal, this flat-bottom hole was drilled from the back surface to a depth of $44.5 \mathrm{~mm}$ from the front surface.

Fig. 8 shows waveforms for selected areas on Plate 6 and Plate 7. The waveforms for Plate 6 have been scaled by $6 \mathrm{~dB}$ for direct comparison to the waveforms for Plate 7.

\section{III.C. Discussion}

\section{III.C.1. Plate 6}

Ear A. Ear A has 5 - 5/8" side-drilled holes at 110, I61, 170, 178, and I86 that show high amplitude. These drilled holes can be seen on the side of the plate in Fig. 3A. The holes show up with high reflection (white) in the C-scan in Fig. 5A. An area around A12 - A22 on Ear A shows an indication in the C-scan in Fig. 5A at approximately $27.5 \mathrm{~mm}$ depth. Other waveforms adjacent to A17 show a similar sharp discontinuity at the same $27.5 \mathrm{~mm}$ depth. This indicates a region of planar inhomogeneity.

In the C-scan, the area around E28 - F27 shows a similar planar indication at 46 $\mathrm{mm}$ depth. In this region, a typical waveform at location E28 is shown in Fig. 8D. Waveforms in this area show a relatively "noisy" response indicating grains or other inhomogeneities through the thickness. For comparison, a "clean" area in Ear A at $\mathrm{J} 40$ can be seen in the waveform in Fig. 8B.

Ear B. Two side-drilled holes at I53 and I7 show high reflection in the C-scan in Fig. 5B. The holes are clearly shown in the photo in Fig. 2B.

A large area around Ear B, hole 1 (the hole in the image in Fig. 5B centered at about E13) shows higher amplitude reflections. A strong reflector occurs at approximately $25 \mathrm{~mm}-28 \mathrm{~mm}$ depth. The shape and constant depth of this reflection is indicative of a planar inhomogeneity.

Another feature found in the C-scan of Ear B is a "noisy" area near K46. This area is characterized by a noisy signal in the top $2 / 3$ of the thickness, again indicating grains or other inhomogeneities.

Ear C. In the C-scan in Fig. 5C, a small area between the two slots in Ear C shows a high amplitude planar indication. The planar indication occurs at approximately $24 \mathrm{~mm}$ depth.

A noisy area occurs around J32. Most of the material noise is located in the top $1 / 3$ of the thickness.

None of the indications found on Plate 6 have reflected amplitudes as high as the reference amplitude measured from a $1 \mathrm{~mm}$ diameter drilled hole. It is safe to conclude that all features found from ultrasonic testing on Plate 6 are either inclusions or distributed microporosity. At this time we cannot distinguish between the two possible types of defects. 


\section{III.C.2. Plate 7}

Ear A has $5-\sim 5 / 8^{\prime \prime}$ side-drilled holes at grid locations I9, I62, 170, 178, and 186 that show high amplitude in the C-scan in Fig. 6B. These holes can be seen on the side of the plate in Fig. 4.

In the $\mathrm{C}$-scan in Fig. $6 \mathrm{~B}$, two data points at $\mathrm{B} 11$ and $\mathrm{A} 10$ show an indication at 20 $\mathrm{mm}$ depth. The waveforms at these two locations are shown in Figs. 7A and 7B. For comparison, the response from a $1 \mathrm{~mm}$ drilled hole at $44 \mathrm{~mm}$ depth is shown in Fig. 7D. Each indication has amplitude equivalent to the $1 \mathrm{~mm}$ diameter drilled hole. The defects at B11 and A10 are most likely on the order of $1 \mathrm{~mm}$ in size and do not appear to be contiguous. The high amplitude reflections result from either a localized porosity layer or an inclusion layer.

In the C-scan in Fig. 6B, the area in Ear A with the least ultrasonic noise occurs around J39. The waveform at this location is shown in Fig. 7C.

Plate 7 has higher material noise than Plate 6 . This is indicated by the comparison of predominant green colors in Fig. 6B to the red colors in Fig. 6A. Figs. $8 \mathrm{~A}$ and $8 \mathrm{~B}$ compare waveforms from the lowest noise locations of Plate 7 to the lowest noise location on Plate 6. Figs $8 \mathrm{C}$ and $8 \mathrm{D}$ compare waveforms from the highest indication areas of Plate 7 and Plate 6. The higher material noise most likely results from higher porosity levels in the bulk of Plate 7. Plate 7 has indications of localized defects similar to the reference $1 \mathrm{~mm}$ drilled hole. Plate 6 did not have any indications of this magnitude.

\section{III.D. Verification by X-ray computed tomography of core samples}

In an attempt to establish a relationship between ultrasonic signals and microstructure, core samples were taken from Plate B at 4 locations. Plate B was a sample cut out of a top plate and is shown in Fig. 9. Ultrasonic testing was performed on a grid using the procedure described above. Core samples were taken as shown in Fig. 9 at locations of particular interest to the ultrasonic inspection. X-ray computed tomography (CT) was performed on the 4 samples. A C-scan of the gridded area of Plate B is shown in Fig. 10. Core samples were taken from locations $\mathrm{K} 26, \mathrm{C} 14, \mathrm{~K} 08$ and $\mathrm{B} 32$. The core samples are approximately $32 \mathrm{~mm}$ in diameter and $63.5 \mathrm{~mm}$ in length.

$\mathrm{X}$-ray computed tomography nondestructively gives a 3D view of the microstructure of the sample. Using a 50 micron voxel size, the field-of-view for the X-ray CT is limited to $48 \mathrm{~mm}$, less than the full length of the core sample. CT slices of sample K08 are shown in Fig. 11. Fig. 11A shows a Z-section through the middle of the core sample. Only $48 \mathrm{~mm}$ from the top side of the sample are shown in the Z-section. Fig. 11B shows an XY-slice of sample K08 at a depth of $z$ $=27 \mathrm{~mm}$. In the CT slices, dark areas correspond to low X-ray attenuation and generally indicate air. The dark areas represent porosity. Approximate sizes of the larger porosity indications as shown in Fig. 11B are $1.5 \mathrm{~mm}$ and $0.3 \mathrm{~mm}$. Fig. 12A shows an $X Y$-slice in sample $\mathrm{K} 08$ at $\mathrm{z}=18.9 \mathrm{~mm}$. A large porosity indication is seen in the $\mathrm{CT}$ at this depth. Fig. 12B shows a profile, listing X-ray 
attenuation values vs. $x$-distance, of the CT slice that cuts across the large porosity indication. The profile location is indicated by the black line in Fig. 12A. The $\mathrm{X}$-ray attenuation value at the location of the porosity indication, where $\mathrm{x}=$ 15 , dips much lower than the surrounding material. However, the attenuation near $\mathrm{x}=15$ does not drop to the zero attenuation as seen outside the part at $\mathrm{x}=$ 30 to $x=35$. If the porosity region near $x=15$ were completely void, the $X$-ray attenuation value would drop close to zero. Because the attenuation value does not drop to zero, what appears to be void is most likely a "spongy" region of porosity that contains both material and void.

Fig. $12 \mathrm{C}$ shows the ultrasonic waveform at location K08. A large reflection is detected at depth $\mathrm{z}=18.9 \mathrm{~mm}$. This reflection likely results from the "spongy" porosity area found in the $\mathrm{CT}$ at the same depth. Without extensive destructive sectioning, it is impossible to conclusively correlate the ultrasonic reflection to the porosity region found in the CT. At best, this correlation can be made only qualitatively.

Fig. 13 presents a qualitative comparison of CT slices to ultrasonic (UT) waveforms at locations K26 and C14. Fig. 13A and 13B compare CT to UT at location K26. This location was chosen for core sampling because it had the lowest ultrasonic response of all other grid points. Fig. 13C and 13D show CT and UT at location C14. The CT slice in Fig. 13C is taken at a depth corresponding to the largest ultrasonic reflection, at approximately $t=130$ in the UT signal in Fig. 13D. The backscatter noise level in the ultrasonic signal at C14 is much higher than at K26. A histogram of attenuation values in the CT slices is shown in Fig. 13E. The peak attenuation value in the histogram of C14 is lower than the peak attenuation value of K26. The lower peak attenuation value in C14 indicates higher porosity in $\mathrm{C} 14$ than in K26. This is qualitatively consistent with the backscatter measured in the ultrasonic signals. This qualitative correlation between microstructure, determined by $\mathrm{CT}$, and contact UT implies that ultrasonic waveforms indicate the porosity level in the cast aluminum.

\section{Ultrasonic field measurements}

To obtain a sampling of quality levels in the set of FAU top plates to be installed at NIF, we traveled to Everson Electric and Metco, two subcontracting companies that provide cast aluminum top plates to NIF. There were two goals for this field work:

1) Assess the overall quality of a sampling of plates. From this assessment, determine if it is possible to extrapolate the results to all the plates to be installed at NIF.

2) Determine if the results of ultrasonic testing on an accessible area of a plate can be correlated to the maximum defect size in the critical area. Contact ultrasonic testing was performed at the Everson and Metco plants according to the same procedure used on Plate 6 and Plate 7. Fig. 14 shows the locations of contact testing on each field-tested plate. The two webs on Ear A between slots are critical areas, identified by structural analysis and cyclic testing 
as the weak points of the plates. In addition, the areas on Ear A near the corner of the slots are also critical areas. All other areas inspected are areas accessible to UT testing after the top plates are installed at NIF. These areas were inspected to determine if plate quality in the accessible areas can be correlated to plate quality in the critical areas. If so, information could be derived on plates already installed at NIF.

Approximately 426 inspection points covering $110 \mathrm{sq}$. in. were recorded for each plate. Testing time lasted approximately 1 hour per plate. Full waveforms were collected at each inspection point. A total of 31 plates were tested in the field, 28$2 \times 2$ plates and 3- $3 \times 2$ plates.

\section{IV.A. Measurement error}

Contact ultrasonic testing has considerable measurement error because of the sensitivity to the operator's pressure, the wear plate of the transducer and the couplant used. To identify the measurement error, three $0.5^{\prime \prime} \times 0.5^{\prime \prime}$ areas at random locations in the center of a plate were marked A, B and C. Each location was tested in order and repeated 12 times i.e. A1, B1, C1, A2, B2, C2, A3, .. A12, $\mathrm{B} 12, \mathrm{C} 12$. The mean and standard deviation FOM (see below) for the 12 measurements are listed in Table 2.

\begin{tabular}{|c|c|c|}
\hline Location & Mean & Std. Dev. \\
\hline A & 45758 & 4711 \\
B & 52956 & 7869 \\
C & 33419 & 6077 \\
\hline
\end{tabular}

Table 2. Mean and standard deviation of UT FOM at 3 random locations.

The standard deviation ranges from $10 \%-18 \%$ of the mean value. This measurement error is fairly normal for contact testing on this type of material.

\section{IV.B. Ultrasonic signal processing}

Two parameters, mean energy and maximum value, are tabulated for the critical and accessible areas of all plates tested. A good figure of merit (FOM) that gives a relative measure of the overall quality of the material is the energy in the reflected ultrasonic signal. This value is derived for the top plates by measuring the energy in the reflected ultrasonic signal between $12 \mathrm{~mm}-60 \mathrm{~mm}$ depth through the thickness of the plate. For the top plates, this value is an indicator of porosity and/or defects through the thickness. A high value arises from large sized porosity, a large number of pores or defects.

A value, $\mathrm{E}$, which is directly proportional to energy, is calculated for each waveform by:

$$
E=\int_{t}\left(v-v_{m}\right)^{2}
$$

where $\mathrm{v}=$ amplitude [volts], $\mathrm{v}_{\mathrm{m}}=$ mean amplitude value [volts] and $\mathrm{t}=$ time. 
The second parameter tabulated for the plates is maximum value or the maximum amplitude in any signal within the area of interest. This value is the maximum signal amplitude that occurs in the reflected ultrasonic signal between $12 \mathrm{~mm}-60 \mathrm{~mm}$ depth through the thickness of the plate. This value is an indicator of the largest-sized flaw in the area of interest. For reference, maximum amplitude values for the 5 reference flat-bottom holes are found in Table 1.

Energy and maximum amplitude for critical and accessible areas of Ear A on each plate, including Plate 6 and Plate 7, are tabulated in Table 3. Columns L-O list the Energy and maximum amplitude in critical and accessible areas, scaled to $54 \mathrm{~dB}$. These values are plotted in Figs. $15-17$. Energy is referred to as FOM on the plot axes. The two types of plates, $3 \times 2$ and $2 \times 2$ are plotted separately on the plots.

Fig. 15 plots maximum amplitude in the critical area vs. FOM in the accessible area. This chart should tell us whether measurements taken in the accessible area are a decent indicator of what the maximum flaw size is in the critical area of the same ear.

Fig. 16 plots maximum amplitude in the critical area vs. FOM in the critical area. This plot should indicate whether maximum flaw size in the critical area is related to the general quality of the plate in the critical area.

Fig. 17 plots FOM in the critical area vs. FOM in the accessible area. This plot should indicate whether the general material quality of the accessible and critical areas is related. If these two parameters are closely related then the material within the ear is more or less of constant quality.

Reasonable correlation is found in each of the plots for $2 \times 2$ plates. Because only 4-3x2 plates were tested, the correlations between FOM and maximum amplitude cannot be made with such insufficient data.

A subsequent advanced statistical analysis of this data was performed and is covered in another NIF report "FAU Top Plate Ultrasonic Data Statistical Analysis" NIF-0081572. 


\begin{tabular}{|c|c|c|c|c|c|c|c|c|c|c|c|c|c|}
\hline order & $\begin{array}{l}\text { Plate } \\
\text { SiN }\end{array}$ & $\begin{array}{c}\text { Other } \\
\sharp\end{array}$ & Size & Location & $\begin{array}{c}\text { Xducer } \\
\text { incidence }\end{array}$ & $\begin{array}{c}\text { Gain } \\
\text { setting } \\
\text { [dB] }\end{array}$ & $\begin{array}{l}\text { Ear A critical, } \\
\text { Energy }\end{array}$ & $\begin{array}{c}\text { Ear A accessble, } \\
\text { Energy }\end{array}$ & $\underset{\text { val }}{\text { Ear A critical, max }}$ & $\begin{array}{c}\text { Ear A accessible } \\
\max \text { val }\end{array}$ & $\begin{array}{l}\text { Ear A critical, } \\
\text { Energy, Scaled }\end{array}$ & $\begin{array}{l}\text { Ear A accessble, } \\
\text { Energy, Scaled }\end{array}$ & $\begin{array}{c}\text { Ear A critical, max } \\
\text { val, scaled }\end{array}$ \\
\hline 7 & 4 & & $2 \times 2$ & Everson & bottom & 54 & 45371.6 & 41976.9 & 60.7954 & 60.8281 & 45371.6 & 41976.9 & 60.8 \\
\hline 5 & 9 & & $2 \times 2$ & \begin{tabular}{|l|} 
Everson \\
\end{tabular} & top & 54 & 55018.7 & 59378.7 & 70.0601 & 53.0596 & 55018.7 & 59378.7 & 70.1 \\
\hline 3 & 22 & & $2 \times 2$ & Everson & top & 54 & 33259,6 & 19481.7 & 47.4849 & 36.4145 & 33259.6 & 19481.7 & 47.5 \\
\hline 19 & 117 & & $2 \times 2$ & Metco & bottom & 54 & 30961.2 & 33086.2 & 76.71 & 62.693 & 30961.2 & 33086.2 & 76.7 \\
\hline 21 & 118 & & $2 \times 2$ & Metco & boltom & 54 & 42281.5 & 54434.9 & 56.8541 & 65.924 & 42281.5 & 54434.9 & 56.9 \\
\hline 18 & 119 & & $2 \times 2$ & Metco & bottom & 54 & 71047.6 & 74130.7 & 79.6468 & 81.454 & 71047.6 & 74130.7 & 79.6 \\
\hline 20 & 120 & & $2 \times 2$ & Metco & bottom & 48.5 & 22190,8 & 23834.6 & 52.348 & 62.0845 & 41799.7 & 44896.0 & 98.6 \\
\hline 23 & 121 & & $2 \times 2$ & Metco & bottom & 54 & 48669.1 & 44240.1 & 75.5244 & 75.4622 & 48669.1 & 44240.1 & 75.5 \\
\hline 25 & 122 & & $2 \times 2$ & Metco & bottom & 54 & 41455.5 & 28240.3 & 65.644 & 41.5703 & 41455.5 & 28240.3 & 65.6 \\
\hline 22 & 123 & & $2 \times 2$ & Metco & bottom & 54 & 50440.3 & 48486.1 & 70.1779 & 66.0231 & 50440.3 & 48486.1 & 70.2 \\
\hline 24 & 124 & & $2 \times 2$ & Metco & bottom & 54 & 52467.6 & 56977.5 & 64.3406 & 70.2719 & 52467.6 & 56977.5 & 64.3 \\
\hline 14 & 125 & & $2 \times 2$ & Metco & bottom & 54 & 64261.6 & 54653 & 61.7606 & 70.7262 & 64261.6 & 54653.0 & 61.8 \\
\hline 17 & 126 & & $2 \times 2$ & Everson & Dottom & 54 & 51542.4 & 51621.3 & 57.1719 & 66.0398 & 51542.4 & 51621.3 & 57.2 \\
\hline 16 & 127 & & $2 \times 2$ & Everson & bottom & 54 & 41155 & 36106.1 & 70.1478 & 63.3673 & 41155.0 & 36106.1 & 70.1 \\
\hline 15 & 128 & & $2 \times 2$ & Metco & bottom & 54 & 35341.2 & 29473.1 & 62.6002 & 57.5766 & 35341.2 & 29473.1 & 62.6 \\
\hline 13 & 129 & & $2 \times 2$ & Metco & bottom & 54 & 65489.5 & 57524.9 & 75.7347 & 74.6451 & 65489.5 & 57524.9 & 75.7 \\
\hline 12 & 130 & & $2 \times 2$ & Melco & bottorn & 54 & 46866.9 & 42880.1 & 93.6515 & 68.626 & 46866.9 & 42880.1 & 93.7 \\
\hline 6 & 131 & & $2 \times 2$ & Everson & bottom & 54 & 57375.5 & 64348.6 & 66.0557 & 71.9931 & 57375.5 & 64348.6 & 66.1 \\
\hline 11 & 132 & & $2 \times 2$ & Metco & bottom & 54 & 40379.7 & 40645.5 & 62.7664 & 64.7221 & 40379.7 & 40645.5 & 62.8 \\
\hline 4 & 139 & & $2 \times 2$ & Everson & top & 54 & 24990 & 40884.8 & 56.158 & 54.1164 & 24990.0 & 40884.8 & 56.2 \\
\hline 30 & 148 & & $2 \times 2$ & Metco & boltom & 54 & 65490.3 & 70558 & 69.9244 & 78.969 & 65490.3 & 70558.0 & 69.9 \\
\hline 31 & 141 & & $2 \times 2$ & Metco & bottom & 54 & 28115.5 & 29549.5 & 53.6577 & 65.6665 & 28115.5 & 29549.5 & 53.7 \\
\hline 32 & 142 & & $2 \times 2$ & Metco & bottom & 54 & 51327.1 & 55868.7 & 67.2355 & 58.1201 & 51327.1 & 55868.7 & 67.2 \\
\hline 33 & 143 & & $2 \times 2$ & Metco & bottom & 54 & 77086 & 74384.8 & 95.4459 & 88.3064 & 77086.0 & 74384.8 & 95.4 \\
\hline 29 & 144 & & $2 \times 2$ & Metco & bottom & 54 & 24191.9 & 24567.9 & 47.0965 & 46.0332 & 24191.9 & 24567.9 & 47.1 \\
\hline 28 & 145 & & $2 \times 2$ & Metco & bottom & 54 & 24167,1 & 25245.6 & 63.2803 & 47.2768 & 24167.1 & 25245.6 & 63.3 \\
\hline 27 & 146 & & $2 \times 2$ & Metco & boltom & 54 & 34235.9 & 37197.3 & 64.9865 & 72.9527 & 34235.9 & 37197.3 & 65.0 \\
\hline 26 & 147 & & $2 \times 2$ & Metco & bottom & 54 & 39217.4 & 42087.4 & 73.7968 & 68.8066 & 39217.4 & 42087.4 & 73.8 \\
\hline B & 1 & & $3 \times 2$ & Everson & bottom & 54 & 52249.2 & 43291.4 & 53.3185 & 70.3245 & 52249.2 & 43291.4 & 53.3 \\
\hline 9 & 45R & & $3 \times 2$ & Everson & bottom & 54 & 38367.5 & 41371,3 & 50.7632 & 44.8297 & 38367.5 & 41371.3 & 50.8 \\
\hline 1 & & 6 & $3 \times 2$ & LLNL & top & 60 & 8167.31 & 2617.24 & 27.4482 & 11.4056 & 4093.4 & 1311.7 & 13.8 \\
\hline 2 & & 7 & $3 \times 2$ & LLNL & top & 54 & 42424.2 & 26489.6 & 57.7643 & 91.4638 & 42424.2 & 26489.6 & 57.8 \\
\hline 10 & $27 R$ & & & Everson & bottom & 54 & 33264.9 & 39738.9 & 55.5932 & 71.6009 & 33264.9 & 39738.9 & 55.6 \\
\hline
\end{tabular}

Table 3. Ultrasonic parameters for all plates tested. 


\section{Conclusions}

A contact ultrasonic testing procedure was developed and performed on 33 fullsized top plates and 3 cut-out samples. Studies were made to correlate the ultrasonic test results to material microstructure in the cast aluminum. Along with the statistical analysis of the ultrasonic data, this work achieved the initial objectives of assessing the quality of FAU top plates. Specific conclusions are:

1) No defects larger than a $1 \mathrm{~mm}$ diameter flat-bottom hole equivalent were found in plates to be cyclically tested at PEER.

2) Ultrasonic testing was found to be a good indicator of material quality in the cast aluminum. Generally, low porosity material gives low ultrasonic reflections, high porosity material gives high ultrasonic reflections. This finding was confirmed with X-ray computed tomography of core samples.

3) No defects larger than a $2 \mathrm{~mm}$ diameter flat-bottom hole equivalent were found in any plate tested. 


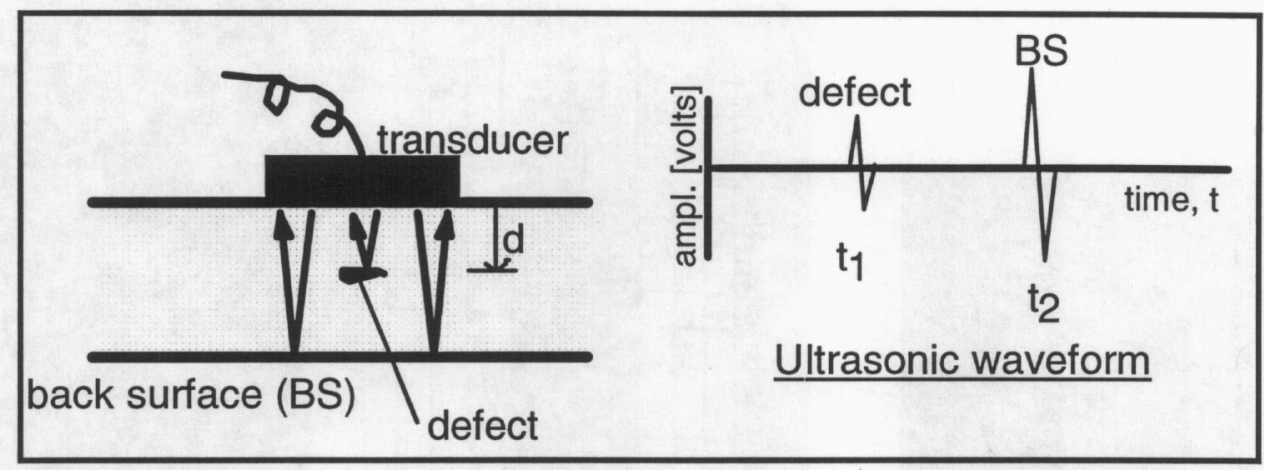

Fig. 1. Contact pulse-echo ultrasonic testing uses a single piezoelectric transducer to send and receive the signal. Reflections are detected from a defect as well as the back surface of the part.

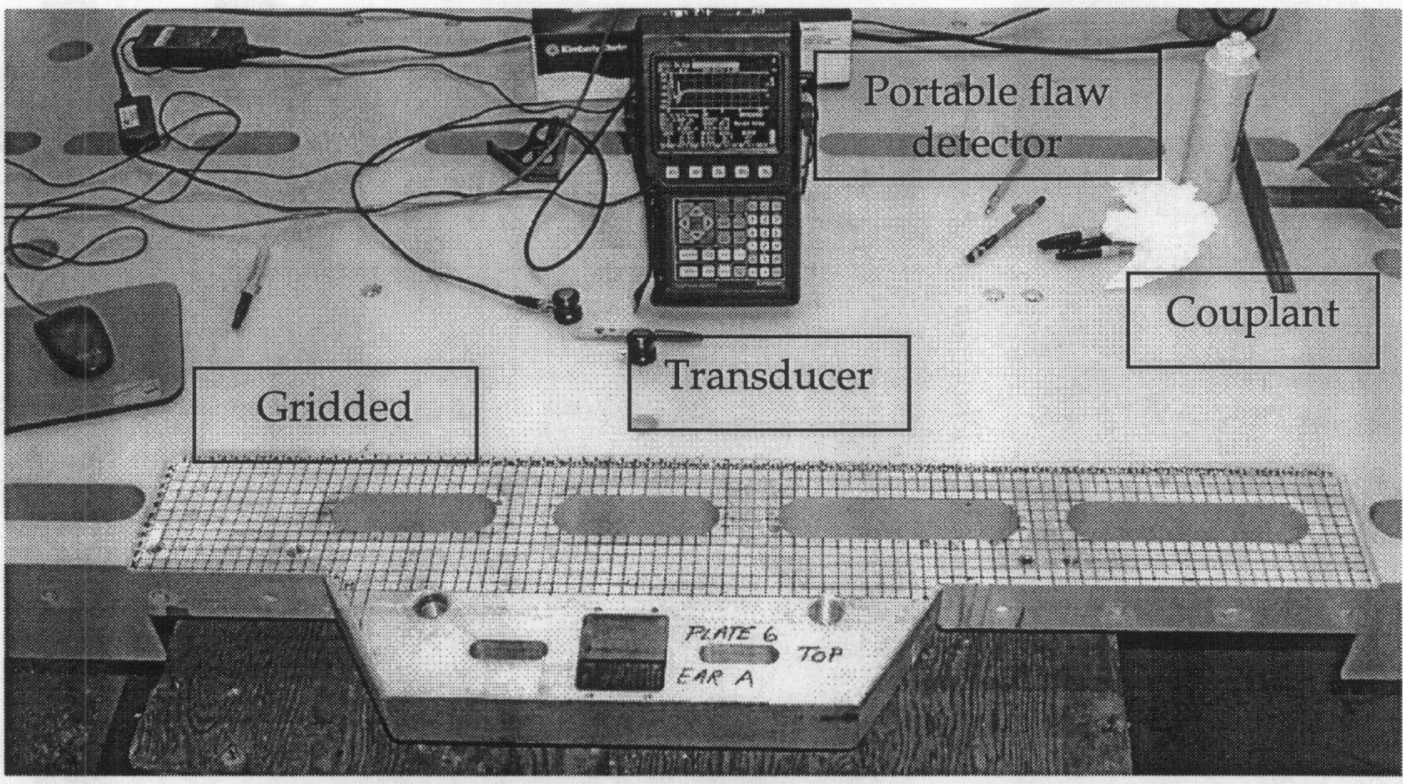

Fig.2. The setup for ultrasonic plate testing includes a portable flaw detector, contact transducer and gel couplant. Waveforms from each location on the grided area are collected on a laptop computer. 


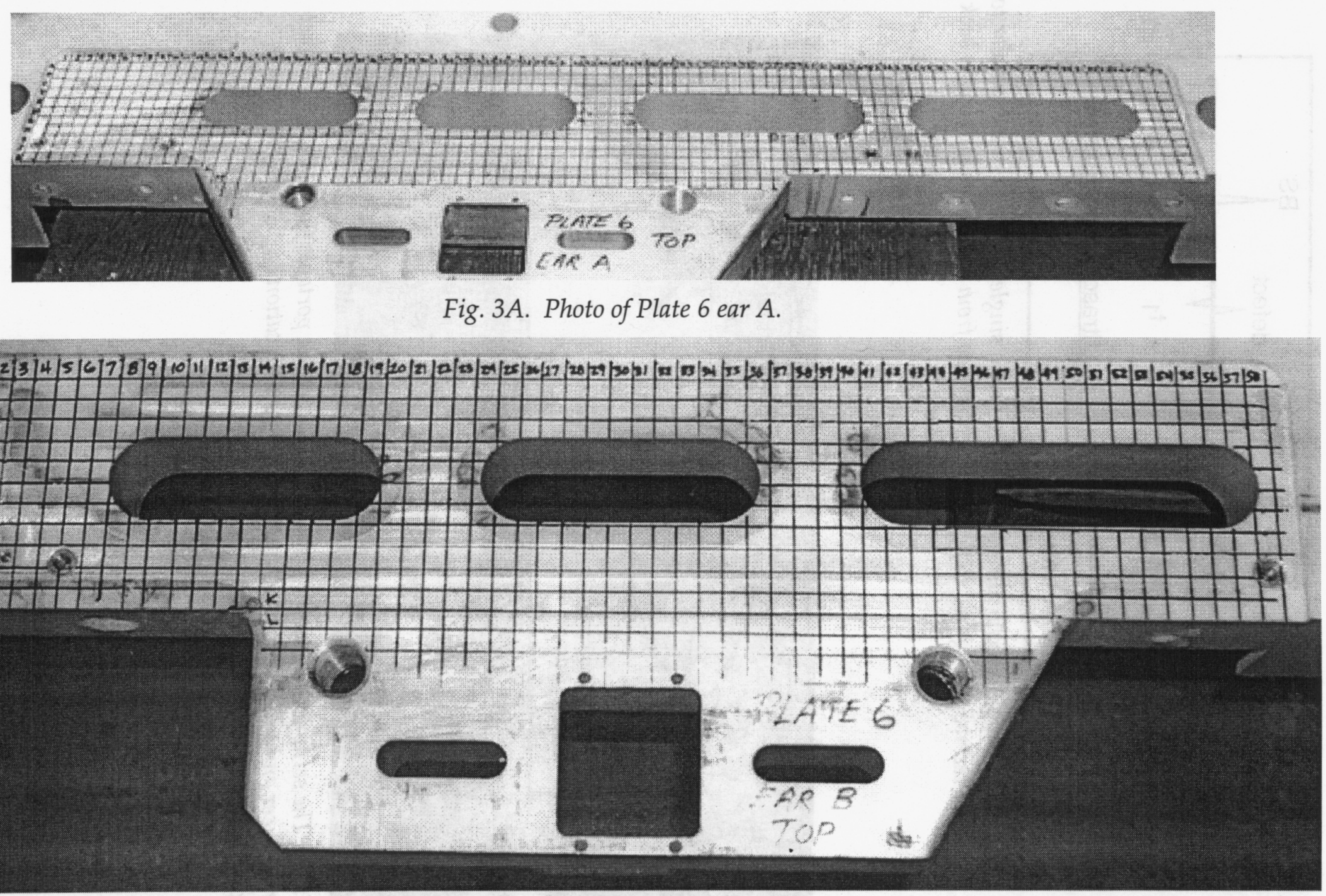

Fig. 3B. Photo of Plate 6 ear B. 


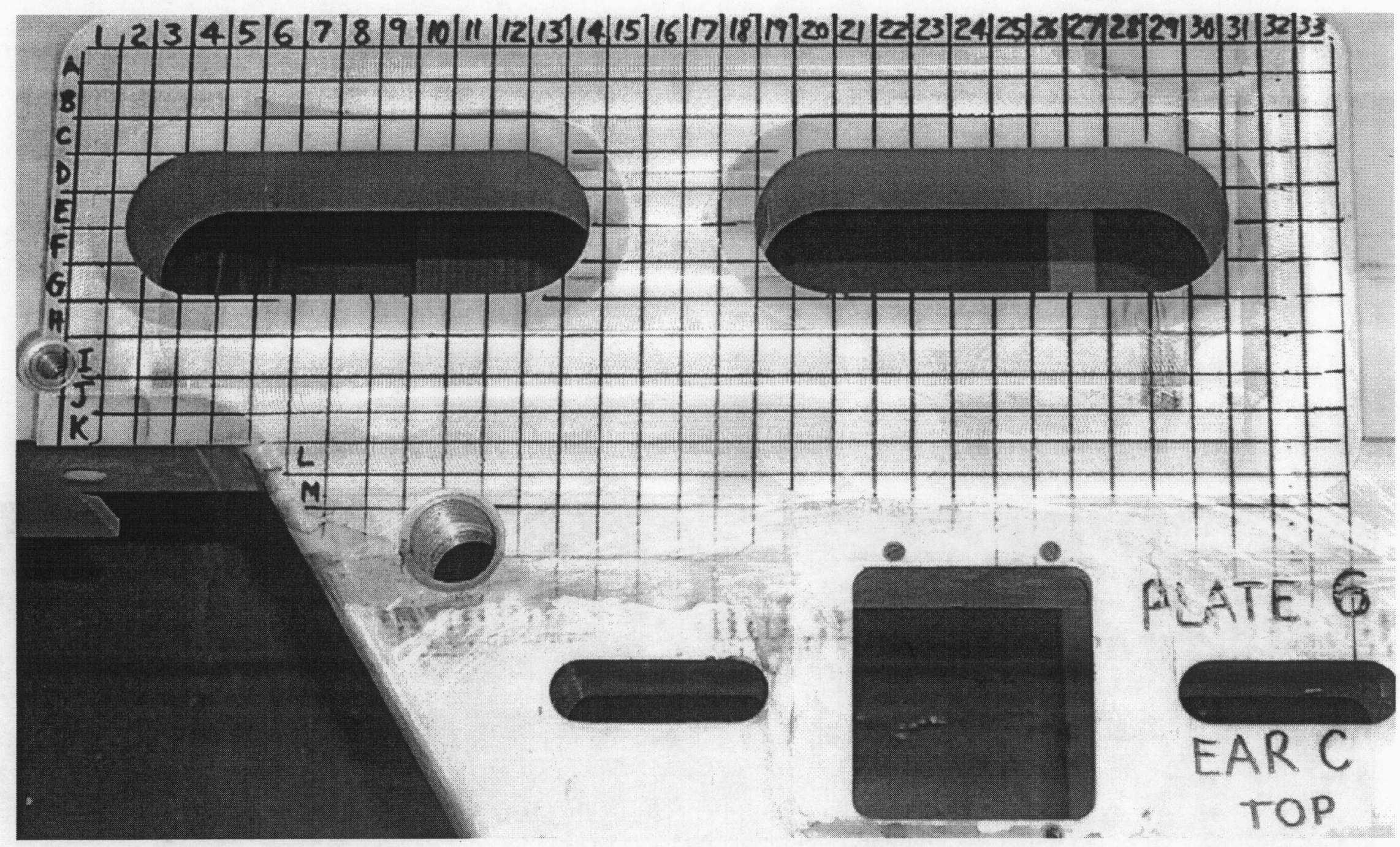

Fig. 3C. Photo of Plate 6 ear C. 


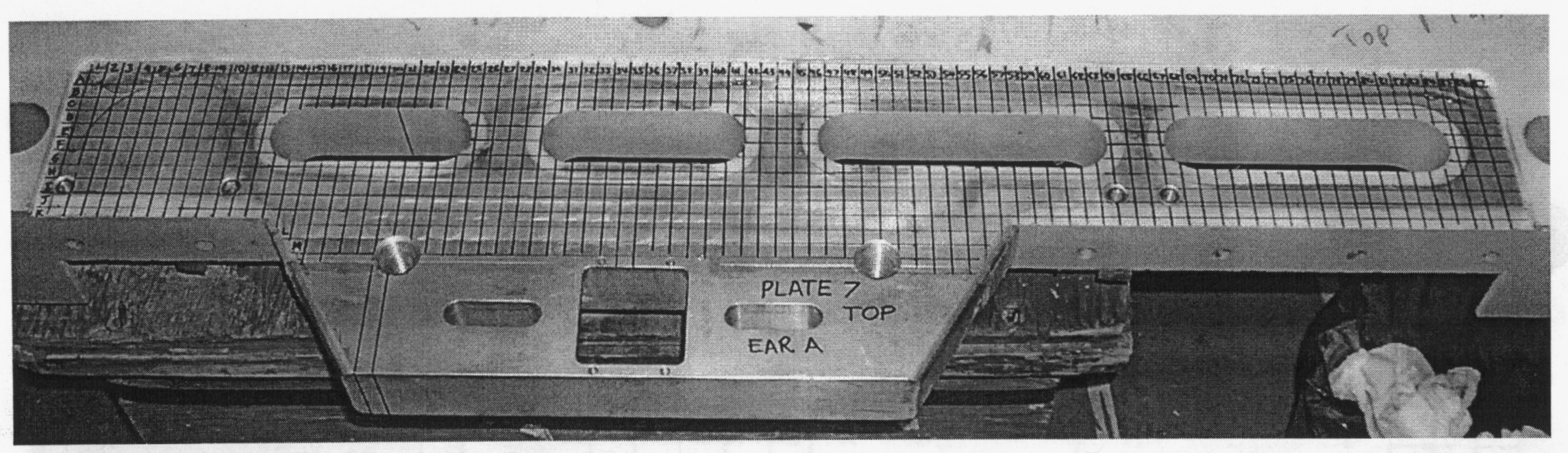

Fig 4. Photo of Plate 7 Ear A. Ultrasonic testing was performed from the top side of the plate. 


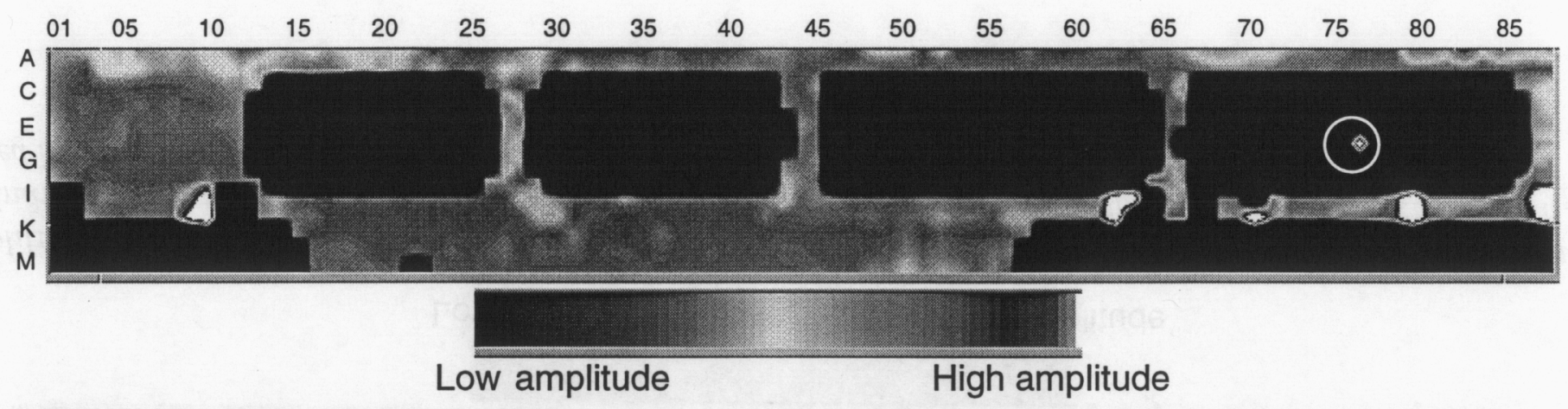

Fig. 5A. Amplitude C-scan of Plate 6, Ear A. A time gate is placed between $12 \mathrm{~mm}$ from the the front surface and $3 \mathrm{~mm}$ from the back surface. The indication circled has been inserted in the $C$-scan image to show the relative magnitude of a reflection from a $1 \mathrm{~mm}$ diameter drilled hole.

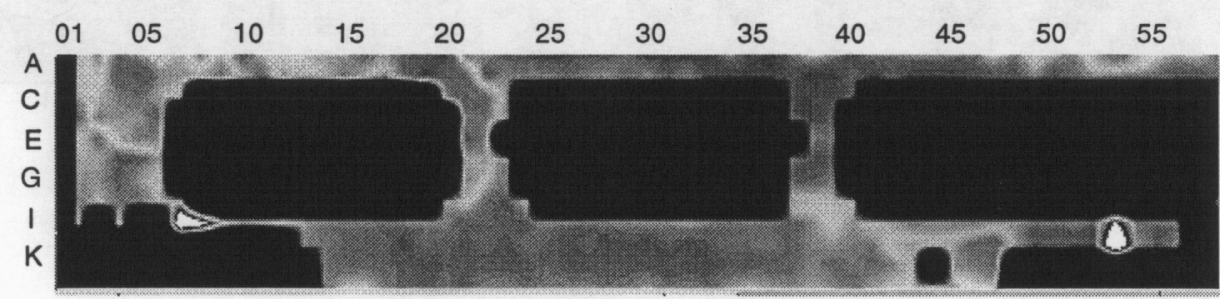

Fig. 5B. Amplitude C-scan of Plate 6 Ear B.

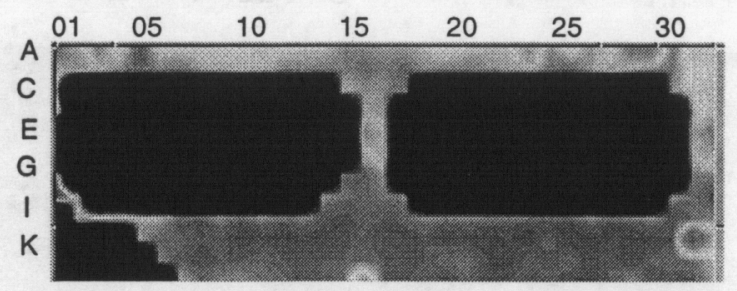

Fig. 5C. Amplitude C-scan of Plate 6 Ear C. 


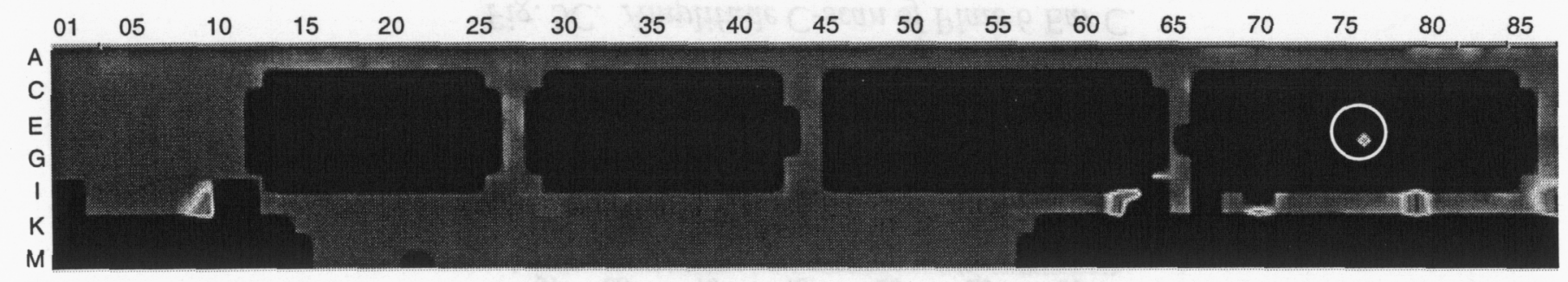

Fig. 6A. Amplitude C-scan of Plate 6, Ear A. This C-scan is shown calibrated to the color scale in Fig. $6 B$.

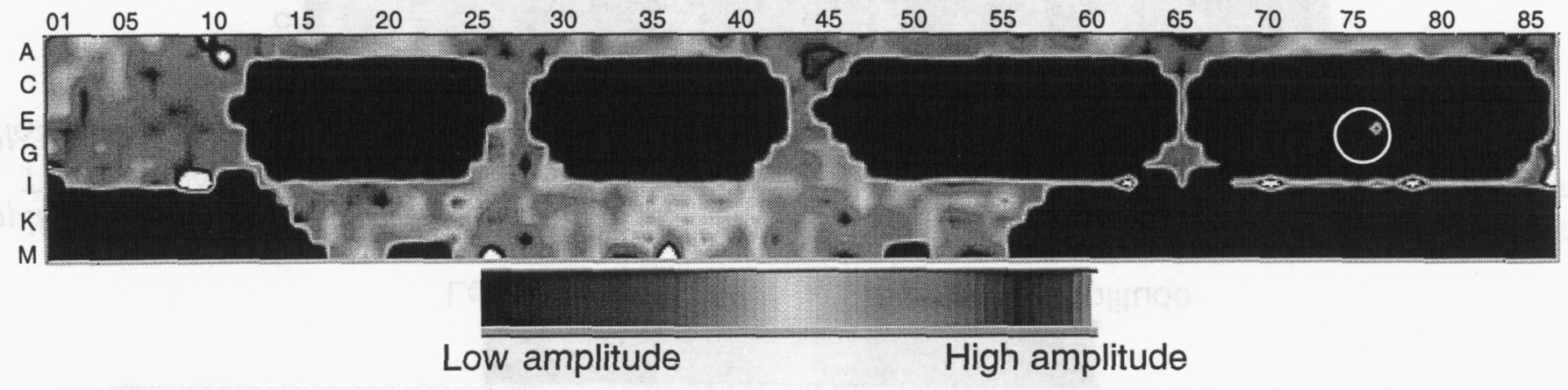

Fig. 6B. Amplitude C-scan of Plate 7, Ear A. A time gate is placed between $12 \mathrm{~mm}$ from the front surface and $3 \mathrm{~mm}$ from the back surface. The indication circled has been inserted in the $C$-scan image to show the relative magnitude of a reflection from a $1 \mathrm{~mm}$ diameter drilled hole. 

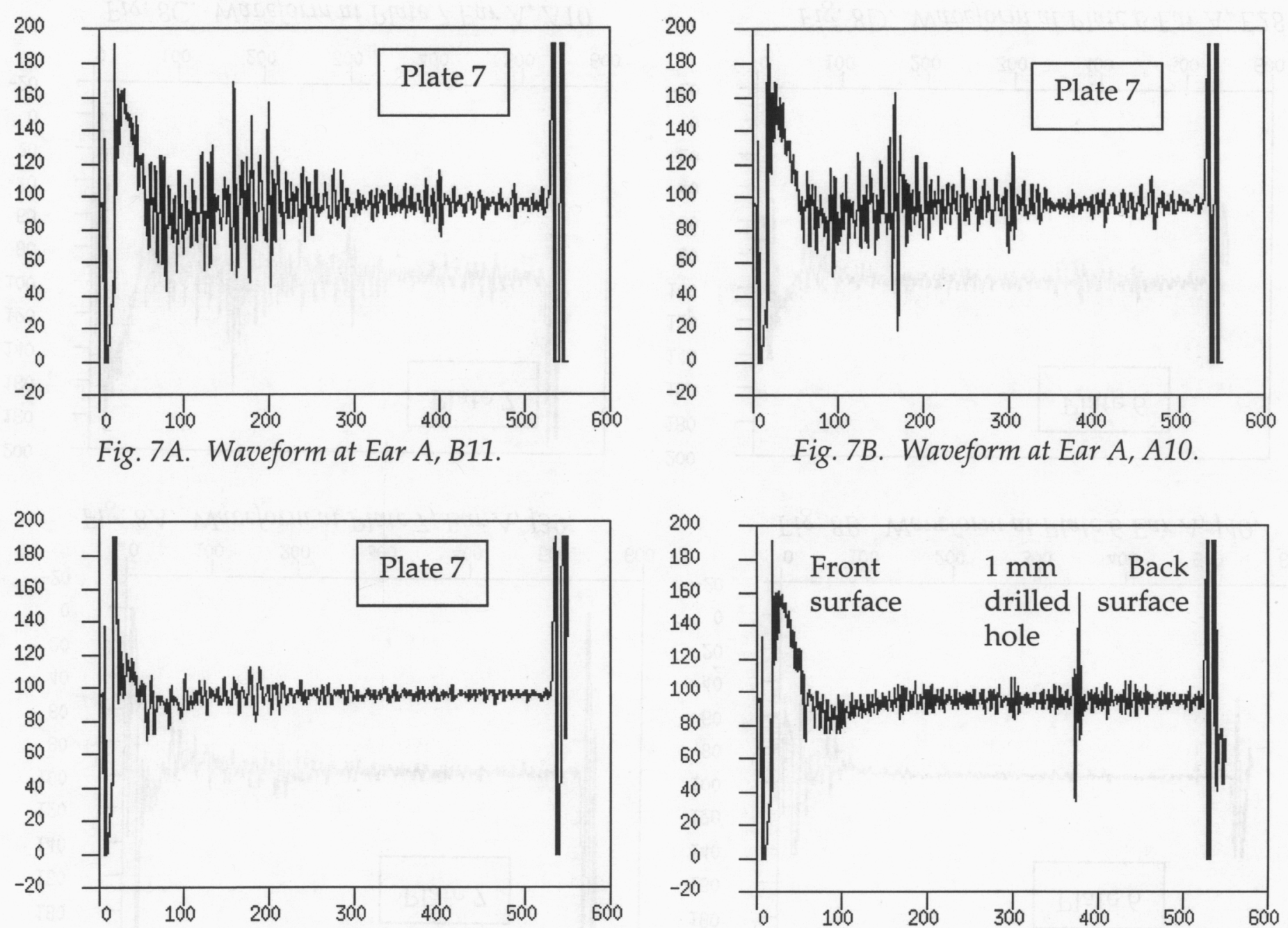

Fig. 7C. Waveform at Ear A, J39.

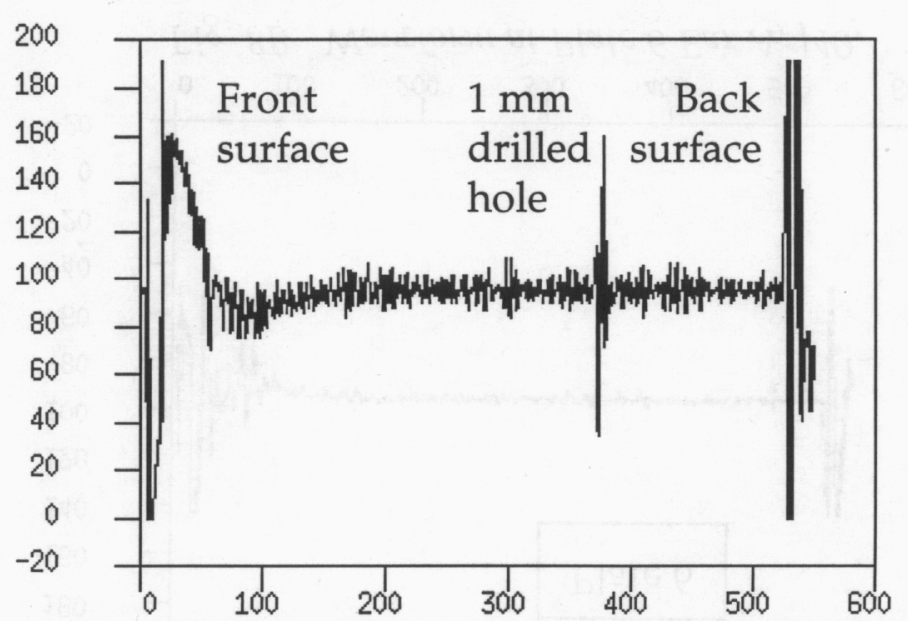

Fig. 7D. Waveform for $1 \mathrm{~mm}$ drilled hole. 


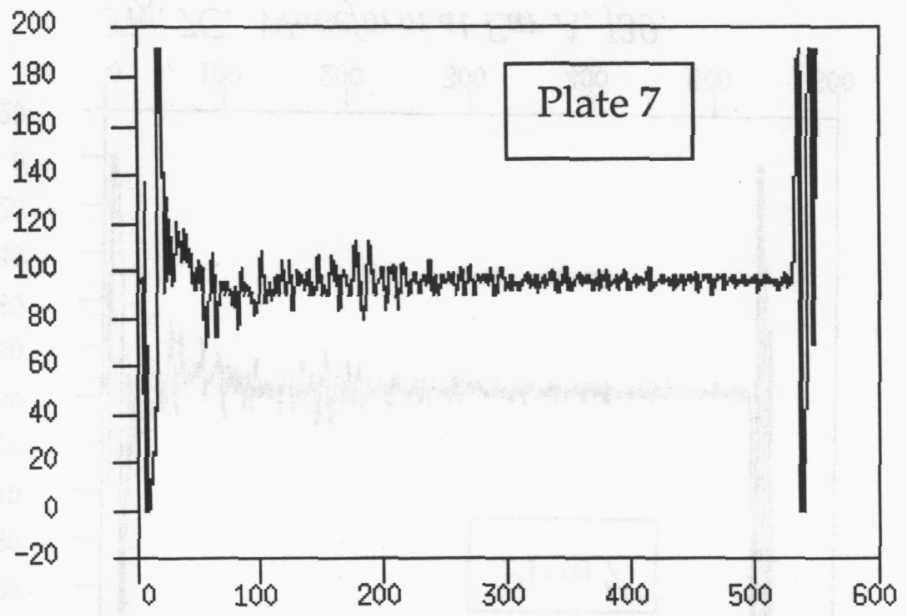

Fig. 8A. Waveform at Plate 7, Ear A, J39.

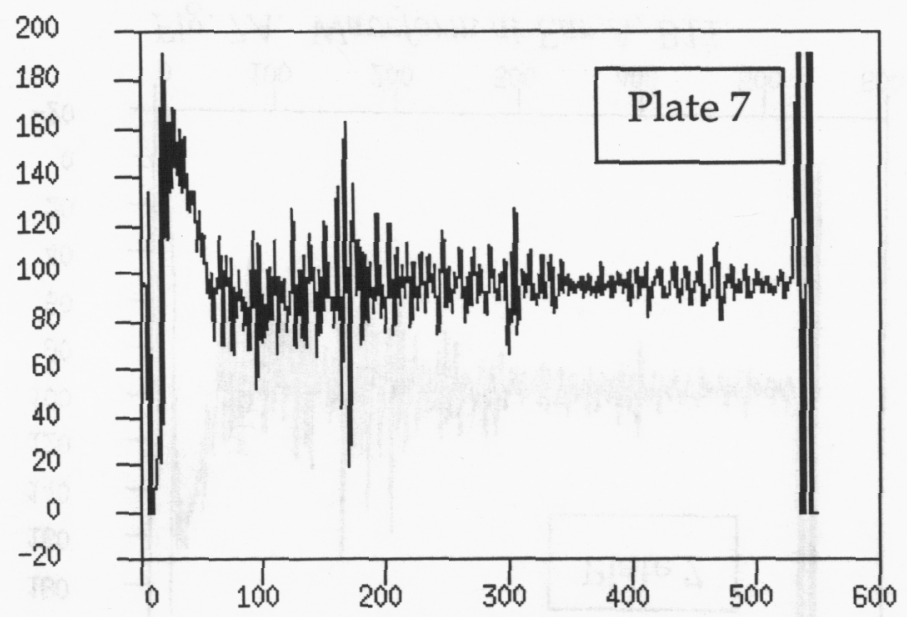

Fig. 8C. Waveform at Plate 7 Ear A, A10.

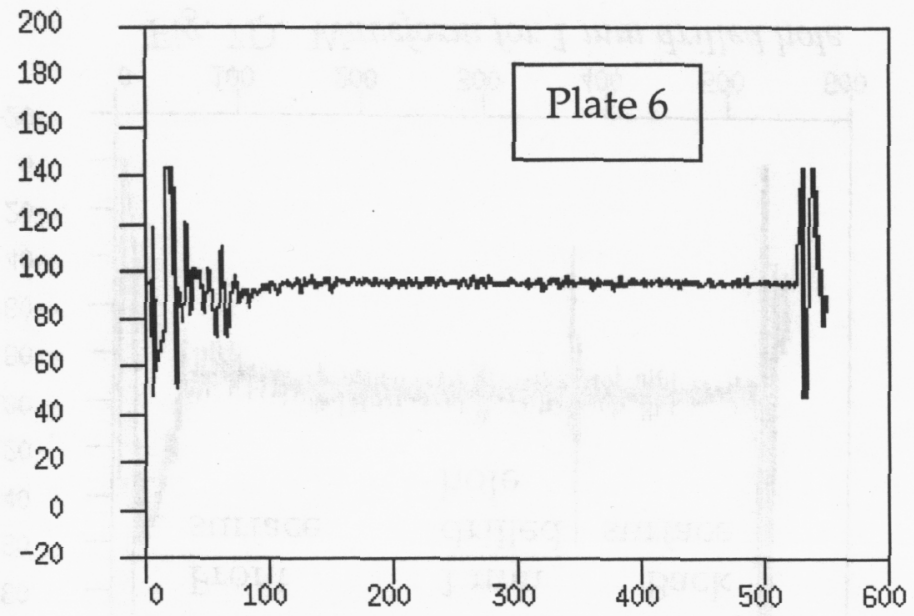

Fig. 8B. Waveform at Plate 6 Ear A, J40.

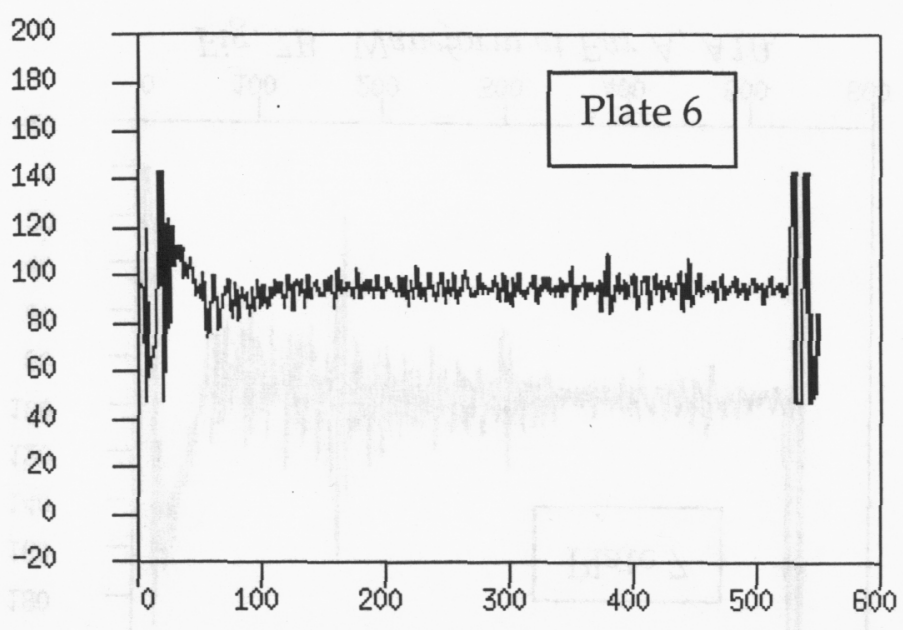

Fig. 8D. Waveform at Plate 6 Ear A, E28 


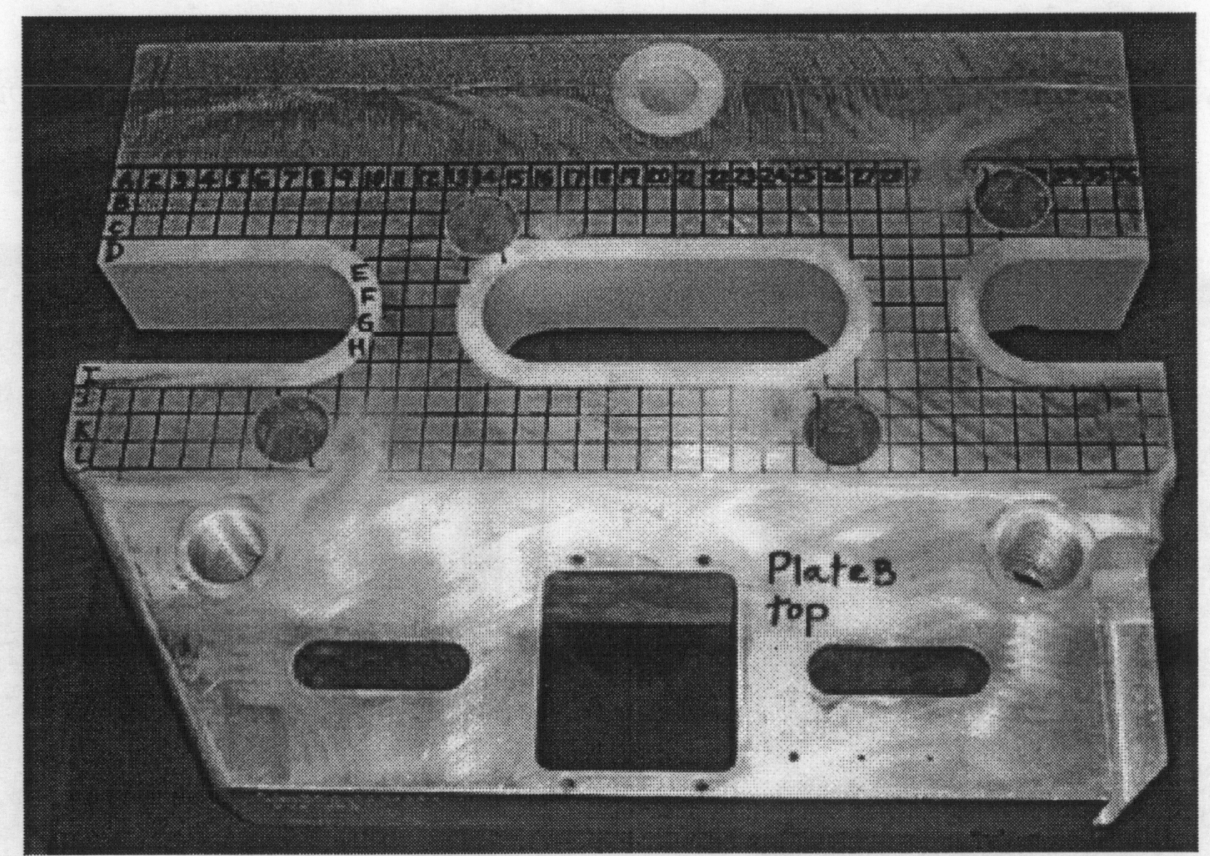

Fig. 9. Core samples from Plate Bat C14, B32, K08 and K26 are used to establish a relationship between ultrasonic waveform and material microstructure.

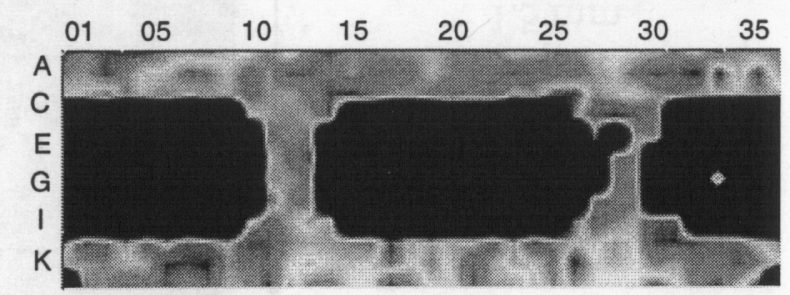

Fig. 10. Contact $C$-scan of Plate B in gridded areas. 


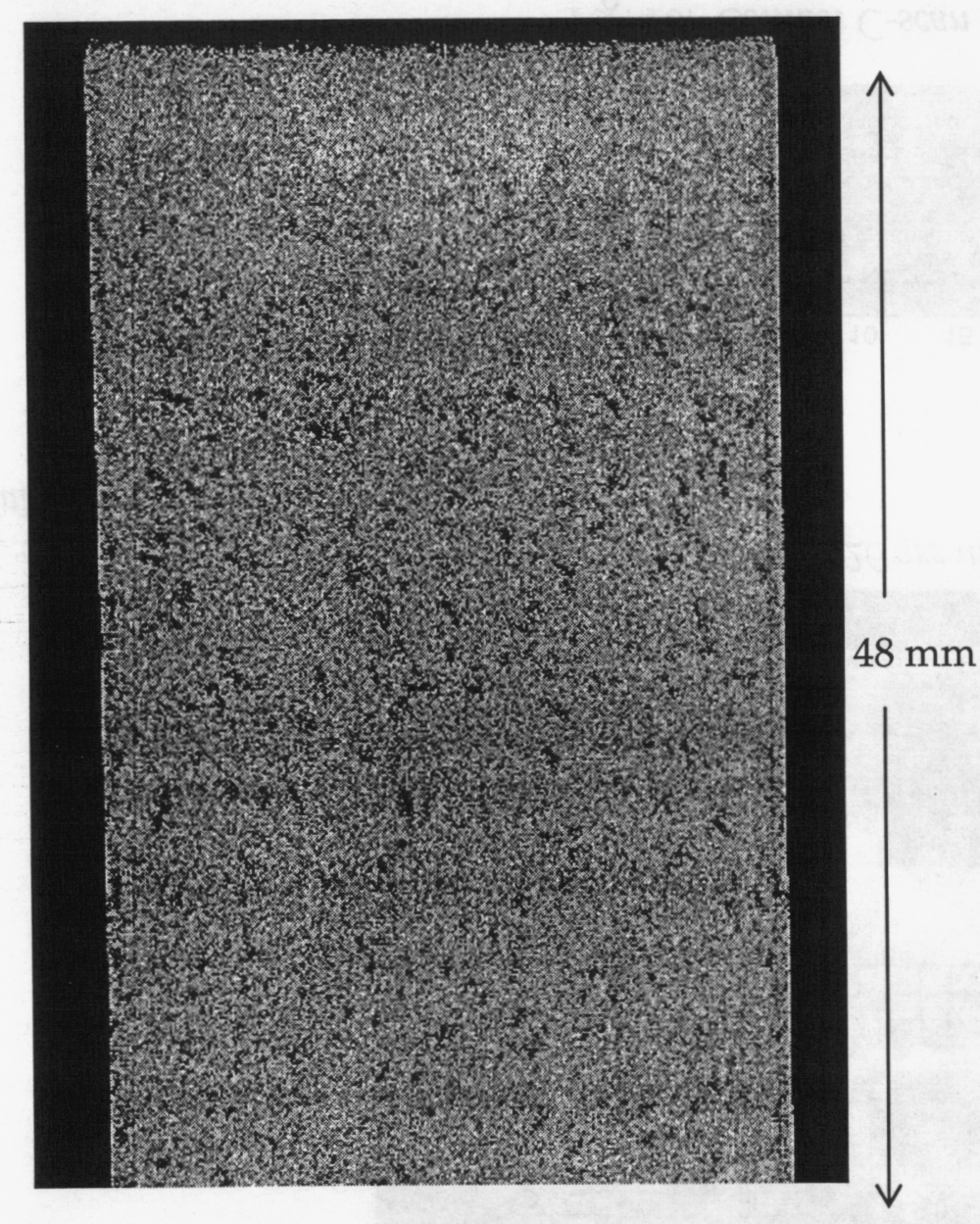

Fig. 11A. X-ray CT Z-slice of Plate B, location K08 at midsection.

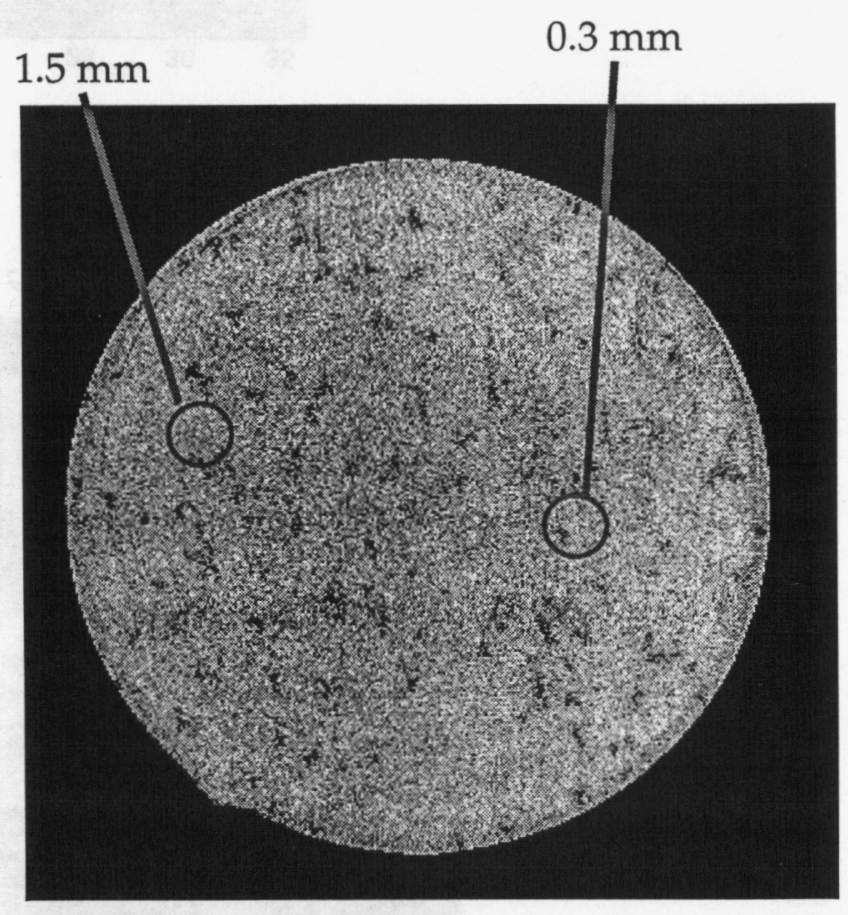

Fig. 11B. CT XY-slice of Plate B, K08 at $z=27 \mathrm{~mm}$. 

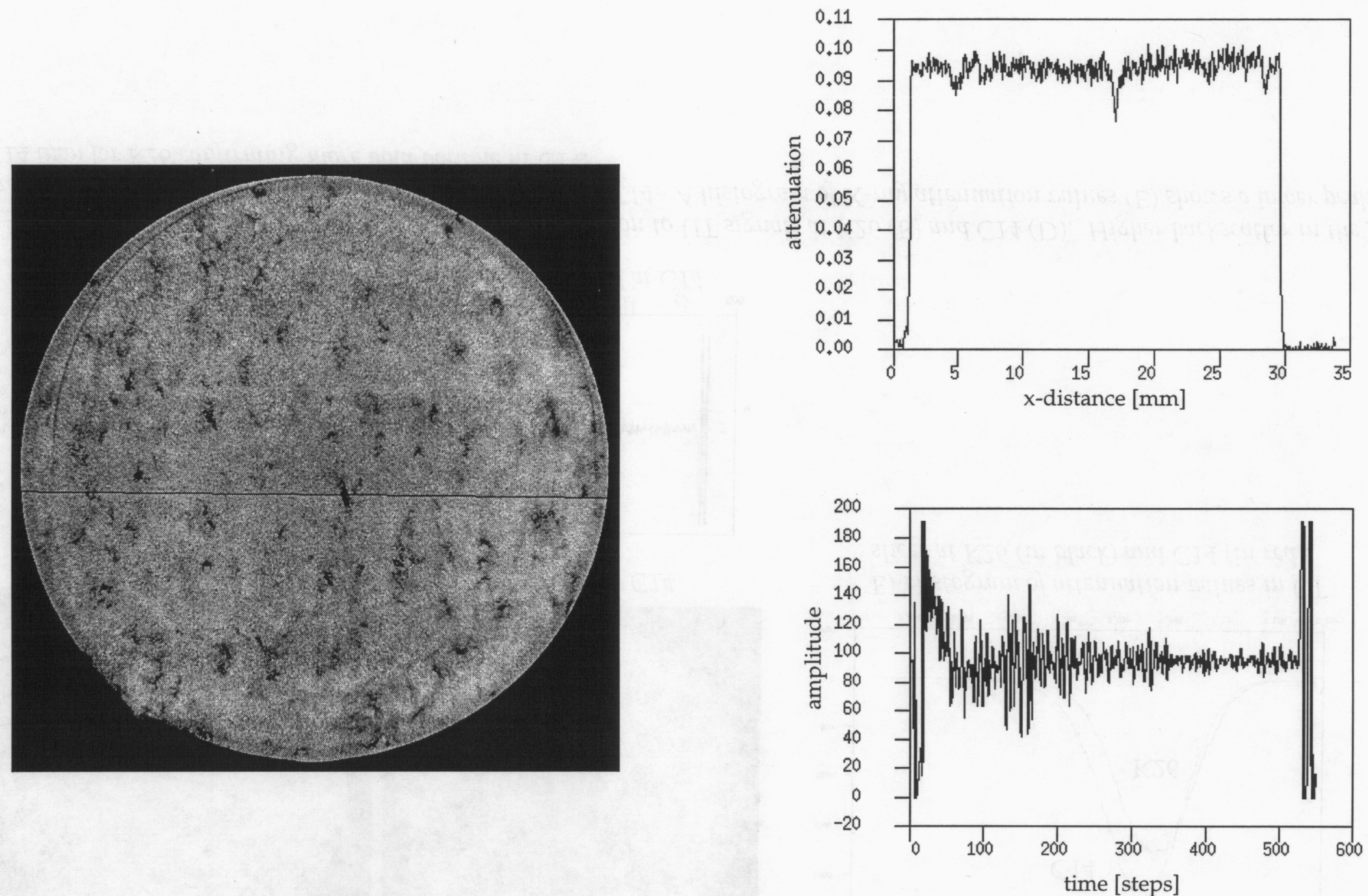

Fig. 12. At location $\mathrm{K} 08$ on Plate $B$, the $C T X Y$-slice $(A)$ shows a large pore. Attenuation values along the line (in black) gives the profile in (B). The ultrasonic signal at K08 is shown in (C). 


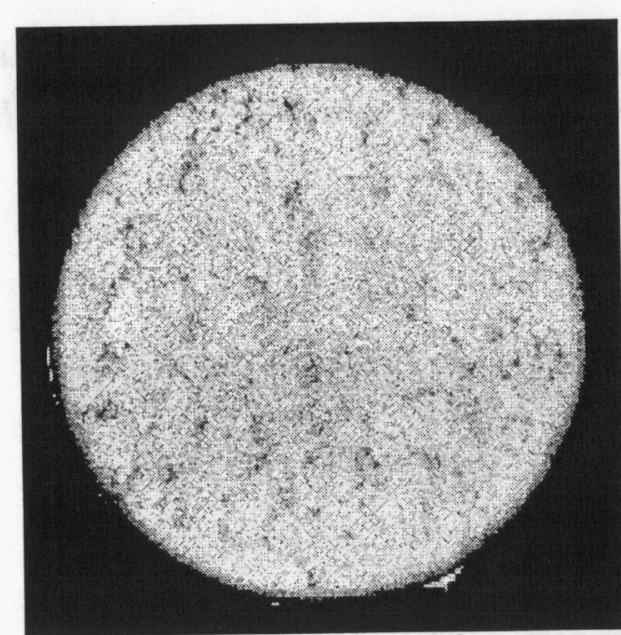

(A) CT slice at K26

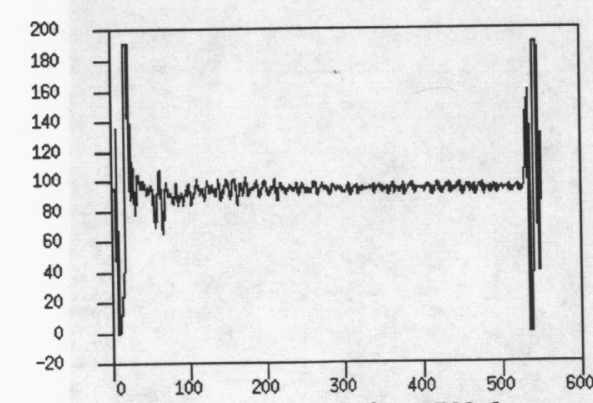

(B) UT signal at K26

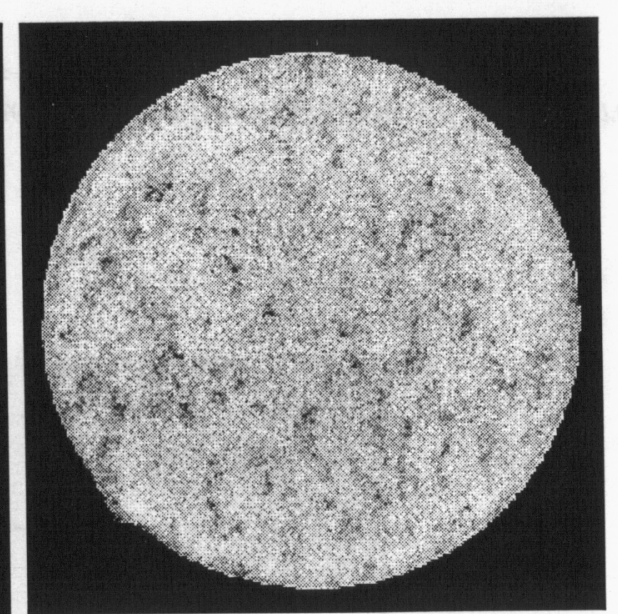

(C) CT slice at C14

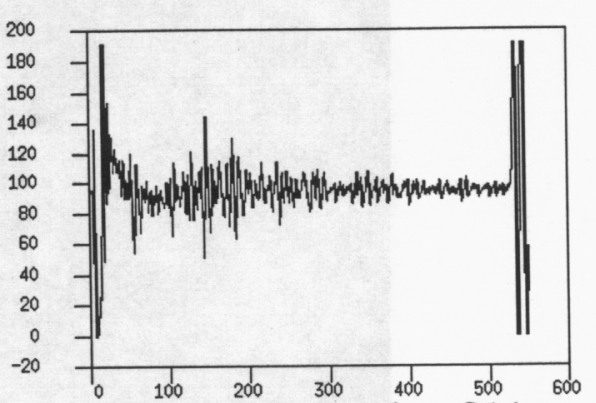

(D) $\stackrel{\mathrm{UT}}{200}^{300}$ signal at $\mathrm{C}^{500}$

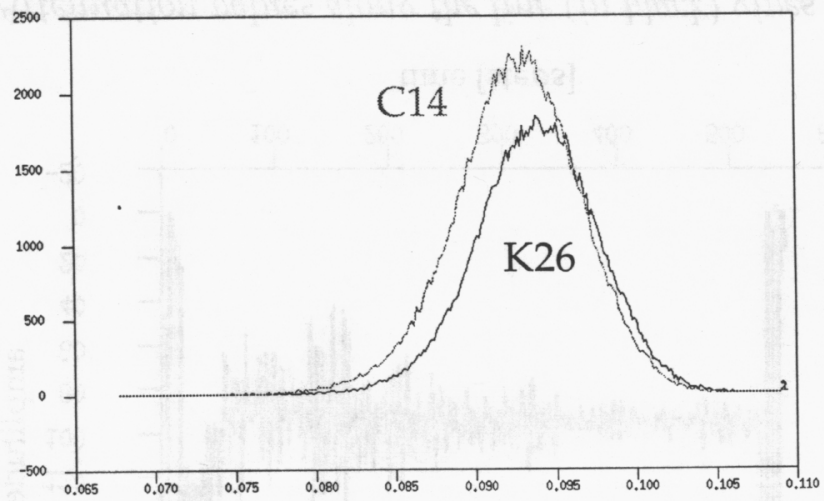

E) Histogram of attenuation values in CT slices at K26 (in black) and C14 (in red).

Fig 13. CT slices at $K 26$ (A) and $C 14$ (C) show good correlation to UT signals at $K 26$ (B) and C14 (D). Higher backscatter in the UT signal in $C 14$ is verified by higher porosity in the CT slice at C14. A histogram of X-ray attenuation values (E) shows a lower peak for C14 than for K26 confirming more void volume in C14. 


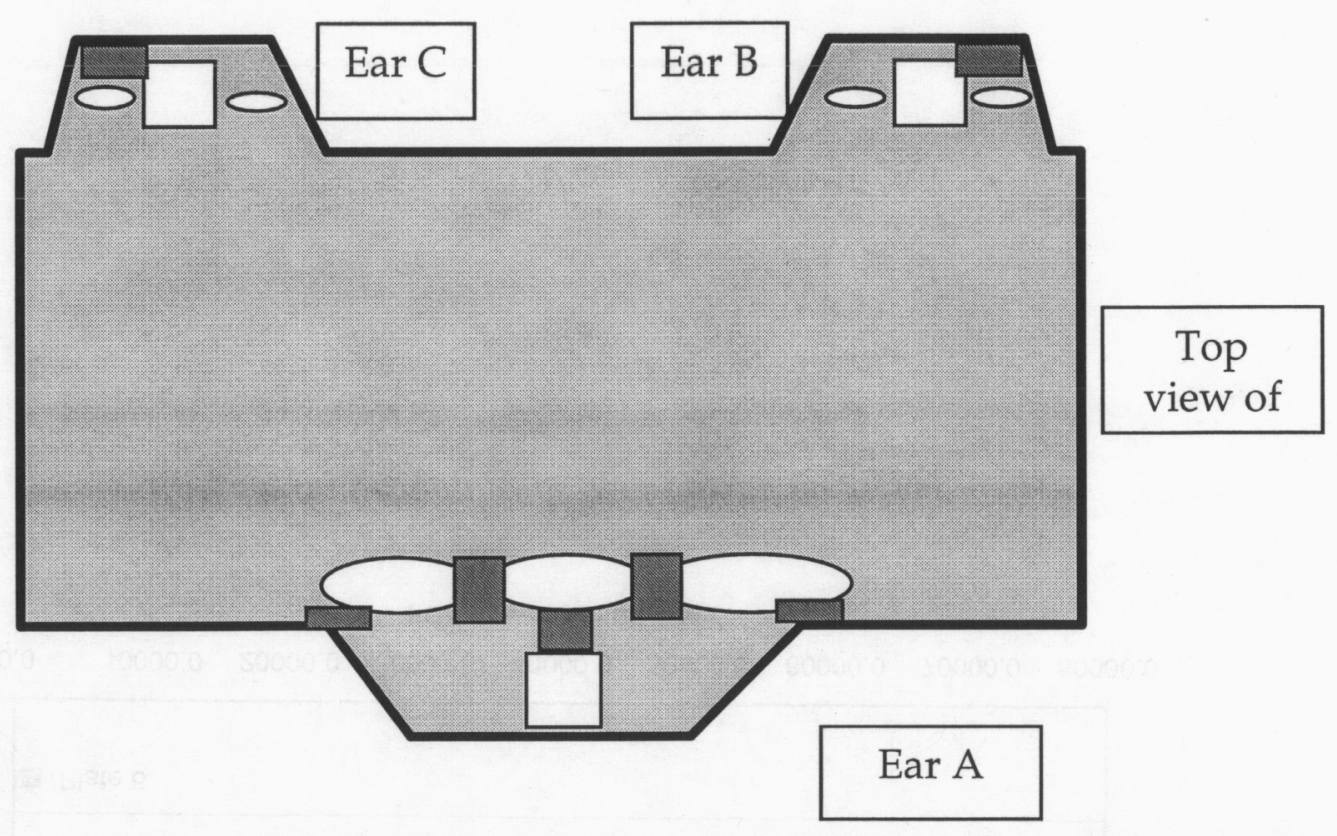

Fig. 14. Test locations for each field-tested plate include critical areas around slots and areas accessible after installation. 


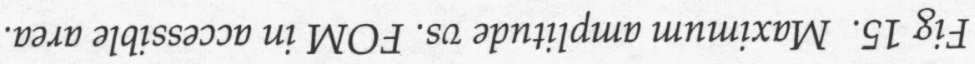

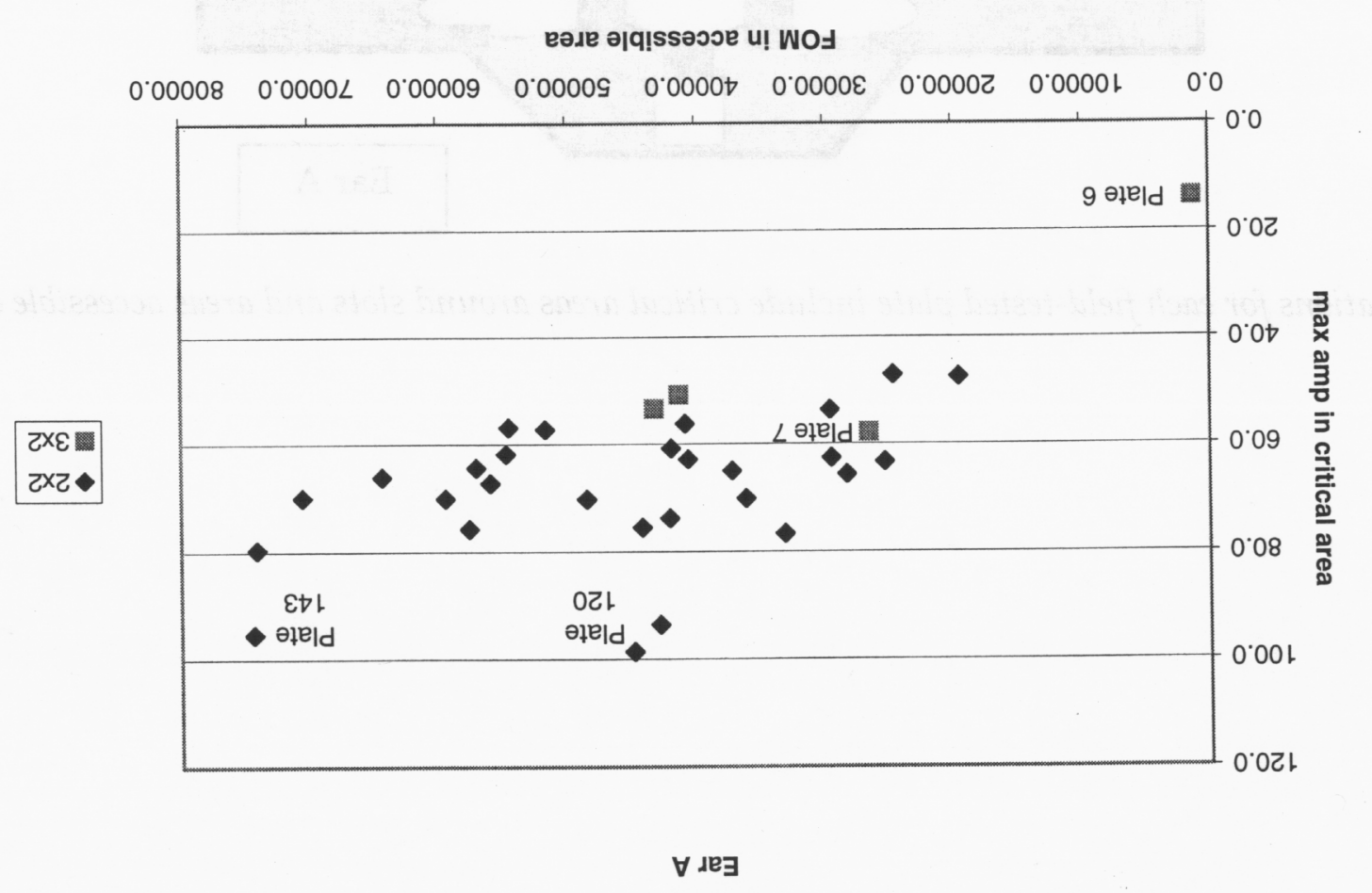




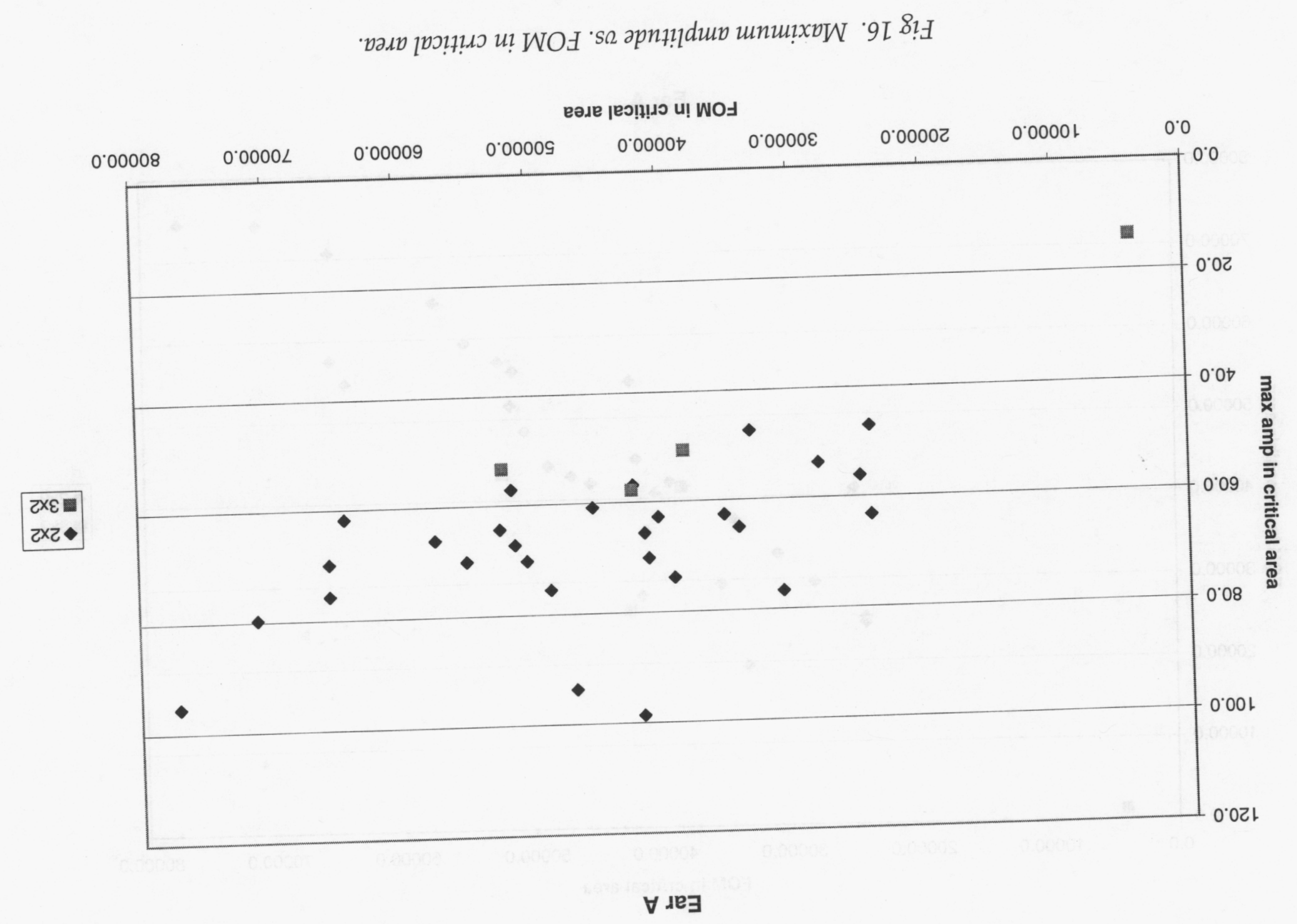


Ear A

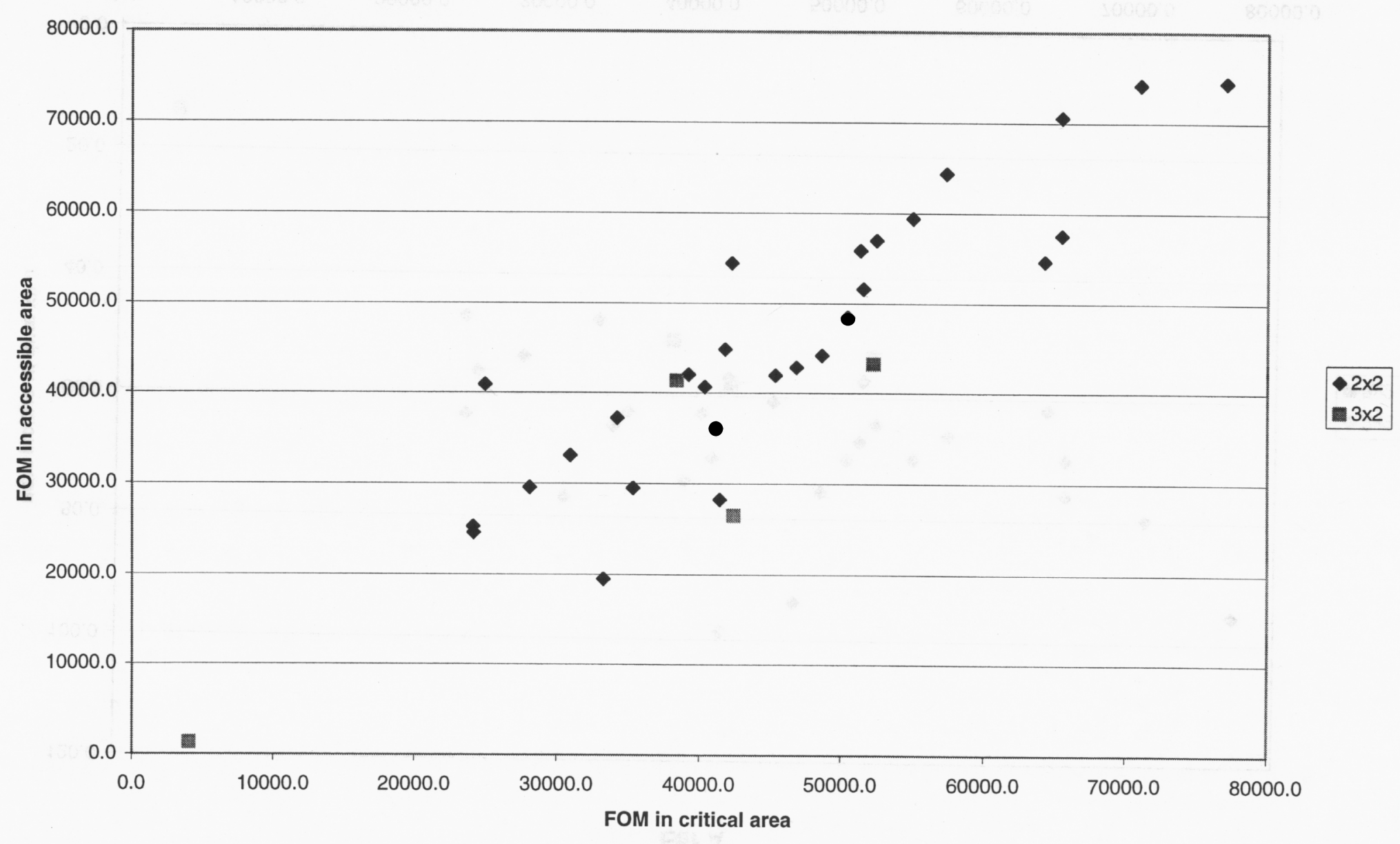

Fig 17. FOM in accessible area vs. FOM in critical area. 